\title{
A review of general practice reports: the need for standardisation
}

\author{
Joe Wilton
}

\begin{abstract}
Fifty general practice annual reports were reviewed with a checklist to determine how much information was commonly included and whether they described the patients, the practice, and practice activity. The reports varied widely: important information was sometimes missing, practice activity was measured in different ways, and terms were often not defined. About half the reports reviewed did not draw conclusions or suggest plans for the future.

Annual reports should include comparable basic information about patients, the practice, and the practice activity to optimise their usefulness in evaluation, planning, and decision making. Many relevant data are available from family practitioner committees and district health authorities.
\end{abstract}

\section{Introduction}

The principal function of an annual report of a general practice is to review practice activity systematically and to determine how the service might be improved. It may also be a historical record of the development of the practice; a morale booster and a reminder to members of the practice that they belong to a team with shared goals; a reference document for new, prospective, and trainee staff; and the basis for an information leaflet for present and prospective patients.

General practices in the United Kingdom started to produce annual reports over 10 years ago, ${ }^{1}$ and increasing numbers of practices now produce them. Indeed, the government's recent review of general practitioners' terms of service states that the production of an annual report should be compulsory, although essential information is concerned only with staff, premises, referral and admissions by specialty, the doctors' other medical commitments, feedback from patients, and some aspects of prescribing. ${ }^{2{ }^{3}}$ It could be argued that the annual report detailed in the government's review is based on value for money whereas an annual report designed by a practice would concentrate on assessing good clinical practice.

General guidelines for producing an annual report have been published, ${ }^{+6}$ but these have not necessarily described how to derive comparable statistics or defined commonly used terms. The Royal College of General Practitioners is presently drawing up an information folder on how to construct an annual report, which will be published this summer. I examined what practices are doing now and assessed what should be included in a standard report.

\section{Department of General Practice, St Mary's Hospital Medical School, Lisson Grove Health} Centre, London NW8 8EG Joe Wilton, MRCGP, lecturer

Br.Med F 1990;300:851-3

\section{Method}

I obtained 50 practice annual reports either from the library of the Royal College of General Practitioners or in response to a letter in the Fournal of the Royal College of General Practitioners. ${ }^{7}$ Reports came from practices in all parts of Britain and inner city, urban, and rural locations. Although the reports were not necessarily a representative sample of all reports produced, they illustrated a comprehensive range of formats. Each report was reviewed with a checklist of information that could be included and the results tabulated.

\section{Results}

PATIENTS

Forty five of the 50 reports surveyed described the practice population by list size, 24 gave a comprehensive breakdown by age and sex, but only nine gave a breakdown by social class. Fifteen reports described the locality, with a few including a map outlining the practice area. Nineteen gave information about the number of temporary residents seen. The annual turnover of patients was given in 18 reports, but the method of calculation was unclear in all but four of these.

\section{PRACTICE}

Thirty two of the reports described the practice's premises, and 41 gave a comprehensive list of staff, although whether staff were part time or full time was mentioned in only one third. The ratio of general practitioners to ancillary staff (whole time equivalents) was rarely mentioned. Staff meetings were listed in 22 reports and teaching commitments in 43 .

Less than a quarter of practice reports described the type of record used (A4 or Lloyd-George). Use of summary cards was discussed in 16 reports, equipment in the practice in 19 , and the presence or absence of computers in 29. Practice policies were outlined in 14 reports and the appointment system used in 23 . Information about finance appeared in half of the reports but was limited to item of service payments only.

\section{PRACTICE ACTIVITY}

Forty two of the reports gave information about the number of consultations and 35 calculated the consultation rate. Only 15 reports made a comparison with national figures. The total number of home visits was given in 39 reports and compared with national figures in nine. Out of hours visits were described in 32 and the use of deputies in 19.

Few reports (16) made any reference to a morbidity register, but half described an audit of management of one or more chronic diseases (usually diabetes). Two thirds of the reports gave figures about uptake of childhood vaccination against diphtheria, tetanus, and pertussis; polio; and measles or measles, mumps, and rubella. Only nine had information about uptake of preschool boosters, and less than a quarter made a comparison with local or national figures. Thirty reports gave information about the numbers of smear tests done but only 19 had information on blood pressure screening.

A few reports included graphs, figures, or photographs. Some reports were clearly a group effort with sections written by various members of the primary 
care team, whereas others had been written by one doctor. Very few reports included any description of changes in the NHS or in the local health authority during the year. Findings were discussed in 28 reports and plans for the future in 25 .

Table I gives further statistics on practice activity.

TABLE I-Information included in annual reports of 50 general practices

No of reports

Prescribing:

Prescription Pricing Authority figures (PACT data)

Breakdown into therapeutic groups

percentage of consultations resulting in a prescription Information on repeat prescriptions

Investigations:

Total performed

As percentage of all contacts with patients

Some breakdown by type (for example, radiography, pathology:

Referrals:

Total referrals to outpatient departments

As percentage of all contacts with patients

Breakdown of outpatient referrals by specialt

Admissions:

Total admissions to hospital

As percentage of all contacts with patients

Breakdown by specialty

Contraception:

Total consultation

Intrauterine contraceptive devices inserted

Termination of pregnancy arranged

Obstetrics:

No of antenatal bookings or deliveries

Place of delivery

Place of deliver

Breast or bottle feeding

Other clinics:

Mention of clinics held

Minor operations performe

Child development checks

Deaths:

No of deaths

Place of death

Cause of death

\section{Discussion}

The number of patients registered with each practice and a breakdown of elderly patients by age is provided quarterly by family practitioner committees. Very young and very old patients increase workload, ${ }^{8}$ so accurate information on numbers is important in identifying the practice's priorities. Many group practice reports emphasise the list size for each doctor, though this probably has little relevance to the day to day running of the practice unless there is a strict individual list system.

The number of temporary residents seen (also given quarterly by the family practitioner committee) is particularly important in tourist areas and inner city practices with many transient patients, where omission of such data would considerably underrepresent the overall workload. Inner city practices often have a high annual turnover, which also increases the workload. Even when annual turnover was mentioned in reports it was not clear how it was calculated. The generally accepted definition of annual turnover is the number of patients joining the list plus the number of patients leaving the list divided by the mid-year list size $\times 100$.

The number of ancillary staff equivalents that the practice used and the maximum theoretically available were often unclear in reports. Efficient employment of staff requires regular update of this information. In addition, descriptive information such as the type of premises, use of Lloyd-George or A4 records, equipment held, and type of appointment system used was often lacking, although this is understandable in practices that have produced reports for some years as repetition of the same information every year becomes tedious.

The starting point for any meaningful discussion about the workload of general practitioners is the total number of consultations and home visits each year and thus the consultation rate. The consultation rate given in the general household survey is the average number of contacts with a general practitioner (in the surgery, at home, or by telephone) per patient per year." None of the reports included telephone contact in their consultation rates, but this is not surprising as it would be difficult to assess accurately. The consultation rate is usually defined as the total number of doctor-patient contacts each year - in the surgery, clinic, or homedivided by the list size.

When reports mentioned a practice nurse it was often unclear whether the nurse's activities were included in the analysis of the overall practice workload, although a practice nurse has a considerable effect on this.

Half the reports gave no information about prescribing despite information being more readily available since the Prescription Pricing Authority was computerised. Every general practitioner is sent a prescribing analyses and cost (PACT) sheet every three months, describing his or her prescribing habits and comparing them with local family practitioner committee and national averages. The emphasis is very much on cost effective prescribing. Two practices had photocopied this information for inclusion in their annual report. Very few practices gave their prescribing rates (percentage of consultations or conditions presented that resulted in a prescription being given). This information is not given in the prescribing analyses and cost sheet and would have to be collected manually.

Few practices gave information on investigations, hospital referrals, or admissions, which would have had to be collected manually and required much extra administrative time. This information will become more important after the institution of the government's white paper and the new contract for general practitioners. ${ }^{2}$

Figures for maternity care, contraceptive services, and night visits are available from family practitioner committees' quarterly statements, and national averages are published monthly. "Preventive medicine is an important part of primary care activity, and uptake of childhood immunisation and cervical smear tests is emphasised in the new contract, with general practitioners being expected to achieve targets. Data on the uptake of childhood immunisation are collated on each district health authority's computer and data on cervical smear tests on each family practitioner committee's computer.

Annual reports are essentially planning documents, yet few reports drew conclusions or outlined plans for the future. The failure to draw conclusions or suggest how to improve performance makes writing a report rather pointless.

In summary, the content and quality of annual reports vary widely. Important information is often missing, and there is a need for standardisation in assessing practice activity. A practice wishing to provide detailed analyses needs to invest effort in gathering information about, for example, the number and type of investigations done, referrals and admissions to hospital, morbidity registers, and audit of the management of chronic illness: evertheless, a basic annual report evaluating good clinical practice can be easily produced as much of the information is already available through other NHS agencies.

The annual report should be aimed at a wider readership than interested practice members-for example, the community health council, the district health authority, and the family practitioner committee. By incorporating local and national variables it should allow the practice team to compare its performance with that of other practices so that 
successes can be celebrated and poor performance acknowledged and improved on. Thus I propose than a basic annual report should contain the information given below. Where relevant, local and national figures should be given for comparison (table II).

TABLE II - National figures on practice activity

\begin{tabular}{|c|c|}
\hline Variable & Value \\
\hline Basic practice data & \\
\hline $\begin{array}{l}\text { Average list size of unrestricted principals in United } \\
\text { Kingdom, } 1987^{\prime 4}\end{array}$ & 1965 \\
\hline $\begin{array}{l}\text { Average No of ancillary staff (as whole time equivalents) } \\
\text { emploved per principal, } 1986^{14}\end{array}$ & $1 \cdot 16$ \\
\hline$\%$ Of practices computerised, England and Wales, $1989^{1 \times}$ & 25 \\
\hline $\begin{array}{l}\text { Practice activity (NHS general practice) } \\
\text { Conculation }\end{array}$ & \\
\hline $\begin{array}{l}\text { Consultations (1987): } \\
\text { Average No of consultations/patient/year }\end{array}$ & 5 \\
\hline$\%$ Of consultations carried out: & \\
\hline In surgery & 78 \\
\hline At home & 15 \\
\hline By telephone & 7 \\
\hline Prescribing: & \\
\hline $\begin{array}{l}\% \text { Of patients consulting doctor who obtained prescription } \\
(1987)^{4}\end{array}$ & 72 \\
\hline Average net ingredient cost/patient $(1987)(\mathfrak{E})^{13}$ & $33 \cdot 17$ \\
\hline Average net ingredient cost/prescription $(1987)(\mathfrak{L})^{13}$ & $4 \cdot 54$ \\
\hline Ne of items prescribed/patient $(1987)^{13}$ & $7 \cdot 3$ \\
\hline $\begin{array}{l}\text { Annual prescribing costs/general practitioner, England } \\
(1989)(\mathcal{L})^{\text {: }}\end{array}$ & 80000 \\
\hline$\%$ Of items prescribed generically $(1989)^{17}$ & 39 \\
\hline Hospital services (as \% of all patients consulting): & \\
\hline $\begin{array}{l}\text { Investigation performed } \\
\text { Outpatient referrals }\end{array}$ & $\begin{array}{l}17 \cdot 4 \\
11 \cdot 0\end{array}$ \\
\hline Outpatient referrals & $11 \cdot 0$ \\
\hline Inpatient referrals ${ }^{1+}$ & $2 \cdot 3$ \\
\hline Immunisation of children: & \\
\hline $\begin{array}{l}\text { Diphtheria, tetanus, polio ( } \% \text { of children born } 1985 \\
\text { immunised } 1987)^{1:}\end{array}$ & 87 \\
\hline Pertussis ( $\%$ of children born 1985 immunised 1987$)^{13}$ & 72 \\
\hline Measles ( $\%$ of children born 1985 immunised 1987$)^{13}$ & 76 \\
\hline Rubella (\% of schoolgirls vaccinated at age 14$)^{11}$ & 86 \\
\hline
\end{tabular}

National demographic data are available elsewhere..$^{911-13}$ Patients-List size, breakdown of patients by age and sex (using the age bands 0-4, 5-14, 15-24, 25-64, $65-74, \geqslant 75)$, numbers of temporary residents seen, and description of locality. Annual turnover should be calculated as described above.

Practice-Numbers of clinical and administrative staff, including hours worked each week. Information about meetings held, equipment (including computers), records and appointment systems, and premises.

Practice activity - Total numbers of consultations in the surgery and at home, the practice consultation rate, and prescribing information (from the prescribing analyses and cost sheet). Figures on contraception and related work, maternity care, night visits (from family practitioner committee returns), use of deputies (from company receipts), childhood immunisation (at 2 and 5 years), and uptake of five yearly smear tests (women aged 25-64, excluding those who have had hysterectomies).

Sadly, the annual report proposed by the government, based on cost effectiveness rather than quality of care, is rather different.

I thank Professor Brian Jarman, Dr Lesley Morrison, Dr Paul Wallace, and Dr John Watson for their help.

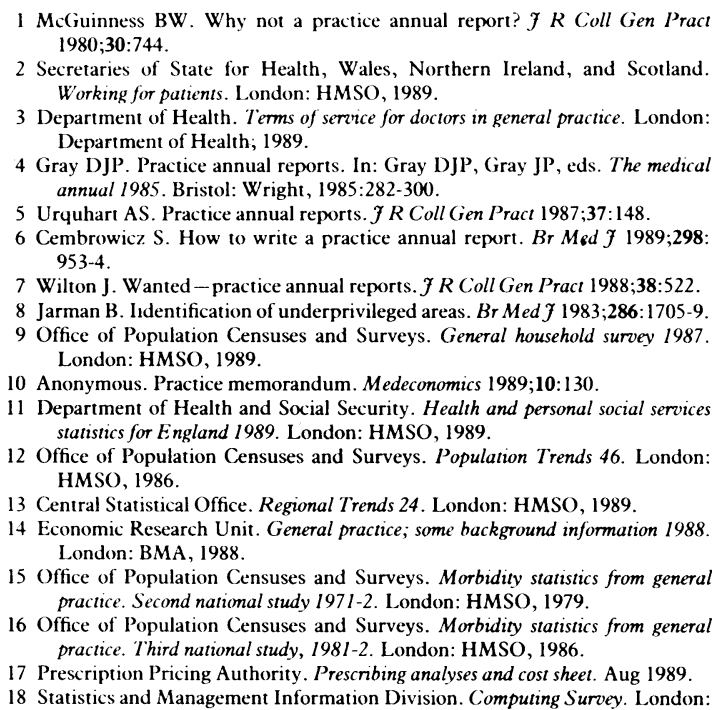
HMSO, 1986.

13 Central Statistical Office. Regional Trends 24. London: HMSO, 1989.

14 Economic Research Unit. General practice; some background information 1988 London: BMA, 1988

15 Office of Population Censuses and Surveys. Morbidity statistics from general practice. Second national study 1971-2. London: HMSO, 1979.

16 Office of Population Censuses and Surveys. Morbidity statistics from general practice. Third national study, 1981-2. London: HMSO, 1986.

17 Prescription Pricing Authority. Prescribing analyses and cost sheet. Aug 1989. 18 Statistics and Management Information Division. Computing Survey. London: Department of Health, 1989

\section{Screening in Practice}

\section{The 1990 contract: its history and its content}

\section{John W Chisholm} A key point in the new $G P$
contract is the requirement to carry out a variety of screening procedures. This article, which looks at the evolution of the contract and the changes that are being introduced, is the first in a series aimed at giving a balanced view of screening in general practice.

\section{Henley on Thames,} Oxfordshire RG9 1PG John W Chisholm, MRCGP, general practitioner
The new contractual arrangements for general practitioners that are to be introduced on 1 April $1990^{14}$ constitute the most significant change to the structure, ethos, and morale of general practice since the implementation of the 1965 charter. But whereas the Family Doctor Charter was prepared by general practitioners, supported by the profession, and negotiated with the government the 1990 changes are being imposed on an unwilling profession.

The 1965 charter resulted in improved morale and increased recruitment to general practice, the establishment of the General Practice Finance Corporation to provide funds for improved premises, and the direct reimbursement of expenditure on staff and premises. It provided a secure foundation for nearly 25 years of sustained development in primary care. The introduction of mandatory vocational training for new entrants to general practice, ${ }^{5}$ the development of primary health care teams, ${ }^{6}$ and the increasing emphasis on prevention and health promotion in general practice ${ }^{7-11}$ all helped to increase standards and to widen the scope of services to patients.
Nevertheless, the profession saw a need to negotiate contractual changes that would also promote a better primary care service. The report of the New Charter Working Group ${ }^{12}$ made detailed proposals that built on the strengths of the 1965 charter, and, as a result of decisions of general practitioners at successive annual and special conferences the profession sought by 1985 to negotiate a wide range of improvements in primary care ${ }^{13}$ These proposals included extending the cervical cytology screening programme, introducing a scheme for paediatric surveillance, encouraging minor surgery, developing the ancillary staff scheme, funding the development of premises, stimulating the introduction of computers into general practice, and reducing the maximum list size.

The government's proposals for change developed more slowly, with the result that for many years the profession's constructive proposals for specific contractual changes to develop general practice were blocked by the government's intention to develop a comprehensive strategy for the future of primary care. In July 1982 the Department of Health and Social 